\title{
Comparison of ramosetron and ondansetron for the treatment of established postoperative nausea and vomiting after laparoscopic surgery: a prospective, randomized, double-blinded multicenter trial
}

This article was published in the following Dove Press journal:

Therapeutics and Clinical Risk Management

\author{
Yong Seon Choi ${ }^{1, *}$ \\ Hye-Min Sohn ${ }^{2, *}$ \\ Sang-Hwan Do² \\ Kyeong Tae Min' \\ Jae Hee Woo ${ }^{3}$ \\ Hee Jung Baik ${ }^{3}$ \\ 'Department of Anesthesiology \\ and Pain Medicine, Anesthesia and \\ Pain Research Institute, Severance \\ Hospital, Yonsei University College \\ of Medicine, Seoul, Republic of Korea; \\ ${ }^{2}$ Department of Anesthesiology \\ and Pain Medicine, Seoul National \\ University Bundang Hospital, \\ Seongnam, Republic of Korea; \\ ${ }^{3}$ Department of Anesthesiology and \\ Pain Medicine, College of Medicine, \\ Ewha Womans University, Seoul, \\ Republic of Korea \\ *These authors contributed equally \\ to this work
}

Background: Postoperative nausea and vomiting (PONV) is a common complication after surgery, which increases physical and psychological discomfort and delays recovery. The aim of this study was to test the hypothesis that ramosetron is comparable to ondansetron for the treatment of established PONV after laparoscopic surgery using a prospective, randomized, double-blinded, noninferiority study.

Methods: Patients who had at least two risk factors of PONV and underwent laparoscopic surgery under general anesthesia were assessed for eligibility. Patients who developed PONV within the first $2 \mathrm{~h}$ after anesthesia received ondansetron $(4 \mathrm{mg})$ or ramosetron $(0.3 \mathrm{mg})$ intravenously in a randomized double-blind manner. Patients were then observed for $24 \mathrm{~h}$ after drug administration. The incidence of nausea and vomiting, severity of nausea, rescue antiemetic necessity, and adverse effects at $0-2$ or 2-24 h after drug administration was evaluated. The primary endpoint was the rate of patients exhibiting a complete response, defined as no emesis and no further rescue antiemetic medication for $24 \mathrm{~h}$ after drug administration.

Results: Among the 583 patients, 210 (36.0\%) developed PONV and were randomized to either the ondansetron $(n=105)$ or ramosetron $(n=105)$ group. Patient's characteristics were similar between the groups. The complete response rate was $44.1 \%$ in the ondansetron group and $52.9 \%$ in the ramosetron group after $24 \mathrm{~h}$ of initial antiemetic administration. The incidence of adverse events was not different between the groups.

Conclusion: We found evidence to support the noninferiority of ramosetron $(0.3 \mathrm{mg})$ compared to ondansetron ( $4 \mathrm{mg}$ ) for the treatment of established PONV in moderate to high-risk patients undergoing laparoscopic surgery.

Keywords: laparoscopic surgery, ondansetron, postoperative nausea and vomiting, ramosetron, non-inferiority, antiemetic

\section{Introduction}

Despite considerable effort in evaluating antiemetic strategies and the development of a new antiemetic class, postoperative nausea and vomiting (PONV) remains one of the most common and distressing complications after surgery. PONV not only increases physical and psychological discomfort but also causes wound dehiscence, dehydration, and electrolyte imbalance, which leads to delayed recovery, prolonged hospital stays, and life-threatening aspiration. ${ }^{1,2}$ Published evidence suggests that prophylactic
Department of Anesthesiology and Pain Medicine, College of Medicine, Ewha Womans University, 107I Anyangcheon-ro, Yangcheon-gu, Seoul 07985, Republic of Korea

Tel +82 226502868

Fax +82 226552924

Email baikhj@ewha.ac.kr 
administration of antiemetic drugs should be considered for patients with two or more PONV risk factors, such as the female gender, nonsmoking, and the use of postoperative opioids. ${ }^{3,4}$ In addition, various approaches to prevent or treat PONV have been studied, especially for high-risk patients, which contribute to early recovery, increased patient satisfaction, and reduced side effects.

Among the currently available antiemetics, 5-hydroxytryptamine receptor $3\left(5-\mathrm{HT}_{3}\right)$ antagonists are frequently used for prophylaxis against PONV and treatment of established PONV. Ramosetron is a newly developed selective $5-\mathrm{HT}_{3}$ receptor antagonist with longer action duration (up to $48 \mathrm{~h}$ ) and higher receptor affinity than its previously developed congeners, including ondansetron. ${ }^{5-7}$ Ondansetron is an effective prophylactic and therapeutic $5-\mathrm{HT}_{3}$ receptor antagonist for the treatment of $\mathrm{PONV} .^{8-10}$ Although ramosetron is superior to ondansetron for preventing PONV, ramosetron and ondansetron have never been compared with respect to their therapeutic efficacy in treating established PONV.

Therefore, we designed a randomized controlled trial to compare the therapeutic efficacy of ramosetron and ondansetron for the treatment of established PONV in patients following laparoscopic surgery under general anesthesia.

\section{Methods}

After obtaining approval from the institutional review boards of Yonsei University Severance Hospital, Seoul National University Bundang Hospital, and Ewha Womans University Mokdong Hospital, a total 610 patients undergoing laparoscopic surgery between July 2015 and September 2016 were assessed for eligibility. An independent institutional review board from all the institutions at which the participating anesthesiologists are affiliated has approved this study. This study was registered at http://ClinicalTrials.gov (registration number NCT03017222).

Written informed consent was obtained from all patients before they were recruited. Patient inclusion criteria were as follows: age 19-65 years, undergoing elective laparoscopic surgery under inhalation anesthesia, surgery duration between $30 \mathrm{~min}$ and $4 \mathrm{~h}$, American Society of Anesthesiologists physical status I or II, and at least two of these risk factors: female gender, history of motion sickness or PONV, nonsmoking, and postoperative opioid use. Patient exclusion criteria were as follows: history of being allergic to $5-\mathrm{HT}_{3}$ receptor antagonists, anticancer chemotherapy history, chronic opioid use, alcohol abuse, drug abuse, administration of antiemetic medication within $24 \mathrm{~h}$ of surgery, steroids $24 \mathrm{~h}$ before or after surgery, presence of renal (serum $\mathrm{Cr}>1.6 \mathrm{mg} / \mathrm{dL}$ ) or hepatic (liver enzymes more than twice the normal value) insufficiency, conversion to open laparotomy, pregnant, breastfeeding, borderline QTc prolongation ( $>430 \mathrm{~ms}$ for male, $>450 \mathrm{~ms}$ for female), and unable to understand pain scoring or express the PONV degree.

\section{Intraoperative and postoperative management}

The anesthetic techniques were controlled at all three institutions. Premedication was not administered. Anesthesia was induced using propofol (1.5-2 mg/kg) and fentanyl ( $1 \mu \mathrm{g} / \mathrm{kg})$ or remifentanil (0.5-1 $\mu \mathrm{g} / \mathrm{kg} / \mathrm{min})$ under standard monitoring; rocuronium $(0.6 \mathrm{mg} / \mathrm{kg})$ was administered to facilitate tracheal intubation. The patient's lungs were ventilated with a tidal volume of $8 \mathrm{~mL} / \mathrm{kg}$ of ideal body weight in $50 \%$ oxygen with air. Respiratory rate was adjusted to maintain an end-tidal $\mathrm{CO}_{2}$ pressure of $35-45 \mathrm{mmHg}$. Anesthesia was maintained with sevoflurane or desflurane and remifentanil $(0.1-0.3 \mu \mathrm{g} / \mathrm{kg} / \mathrm{min})$. For management of postoperative pain, a single bolus dose of fentanyl $(1 \mu \mathrm{g} / \mathrm{kg})$ was administered intravenously $15 \mathrm{~min}$ before the end of surgery, and remifentanil intravenous infusion was stopped. Fentanyl (15-20 $\mu \mathrm{g} / \mathrm{kg}$ at $2 \mathrm{~mL} / \mathrm{h}, 0.5 \mathrm{~mL}$ bolus, $15 \mathrm{~min}$ lock-out time, total $100 \mathrm{~mL}$ ) was used in intravenous patient-controlled analgesia (PCA) pumps if indicated to control acute postoperative pain.

After extubation and transfer to the postanesthesia care unit (PACU), the patients were monitored with routine care and supplementary oxygen through a face mask. During PACU care, if patients developed nausea with numerical rating scale $(\mathrm{NRS}) \geq 4$ or vomiting within $2 \mathrm{~h}$ postoperatively, the therapeutic intervention designed to treat PONV ensued. The patients were randomly allocated into one of the two groups: the ondansetron group (Zofran ${ }^{\circledR} 4 \mathrm{mg}$ ) or ramosetron group (Nasea ${ }^{\circledR} 0.3 \mathrm{mg}$ ), using computer-generated random number codes. When nausea of NRS $\geq 4$ or vomiting still existed, metoclopramide (10 mg) as additional rescue antiemetic was administered and recorded. If PONV did not develop within $2 \mathrm{~h}$ postoperatively, we excluded the patient from study enrollment and administered prophylactic antiemetic agents, given the presence of the relevant risk factors for PONV. The study drugs were prepared in identical syringes and administered by the personnel who were not involved in this study. All patients, physicians, and investigators collecting data were blinded to group assignments.

\section{Outcomes}

The primary outcome variable was a complete response rate, defined as no retching and/or vomiting and no secondary rescue antiemetic administration. The secondary outcome 
variables were incidence and severity of nausea, incidence of retching and/or vomiting, need for additional antiemetics, pain score, and requirements of rescue analgesics. The intensity of nausea was graded on an NRS using an 11-point scale, with $0=$ no nausea to $10=$ worst possible nausea. The severity of nausea was determined according to NRS scores: mild (1-3), moderate (4-6), and severe (7-10). Pain intensity scores were measured on a visual analog scale (VAS) that ranged from $0 \mathrm{~mm}$ (no pain) to $100 \mathrm{~mm}$ (worst pain imaginable). The investigator blinded to group allocation evaluated incidence and severity of nausea, retching and/or vomiting, need for additional antiemetics, pain intensity, rescue analgesic, and adverse events for $24 \mathrm{~h}$ after administration of the study drug, which was divided into two intervals: $0-2 \mathrm{~h}$ and $2-24 \mathrm{~h}$.

\section{Statistical analysis}

Statistical analyses were performed using SAS version 9.4 (SAS Institute Inc., Cary, NC, USA). This study was performed as a non-inferiority trial, designating ondansetron, the commonly used drug for treating PONV, as the comparison for the effects of ramosetron toward established PONV. A previous study demonstrated a complete response rate of $45 \%$ with ondansetron (4 mg) treatment for established PONV. ${ }^{9}$ As there was no previous study regarding ramosetron treatment for established PONV, a complete response rate was assumed as 55\% and defined the margin of non-inferiority at an absolute risk difference of $10 \%$. Therefore, we calculated that a study with 95 patients per group would have at least $80 \%$ power, with one-sided type I error of 0.025 , using a noninferiority test. Taking into consideration a $10 \%$ dropout rate, we decided to enroll 105 patients in each group. Categorical variables were analyzed using chi-square test or Fisher's exact test and shown as number and percentage. Continuous variables were expressed as mean \pm standard deviation or median [interquartile range] according to the normality, using Student's $t$-test or Mann-Whitney $U$-test, as appropriate. $P$-values of $<0.05$ were considered significant.

\section{Results}

A total of 610 patients were assessed for eligibility; 210 of the 583 patients observed for $2 \mathrm{~h}$ postoperatively at PACU were enrolled in this study and were randomly assigned to two treatment groups (Figure 1). After randomization, one patient withdrew consent, and three patients were excluded from the final analysis due to use of prohibited drugs without notification to the investigator; the remaining 206 patients completed the study. The baseline characteristics, including history of PONV or motion sickness, anesthetic, operative, and postoperative data, were similar between the groups (Table 1). Fentanyl-based intravenous PCA was used in $62.6 \%$ of all patients. Although there was a higher trend of intravenous PCA use in the ondansetron group, it was not statistically significant $(P=0.08)$. The number of patients

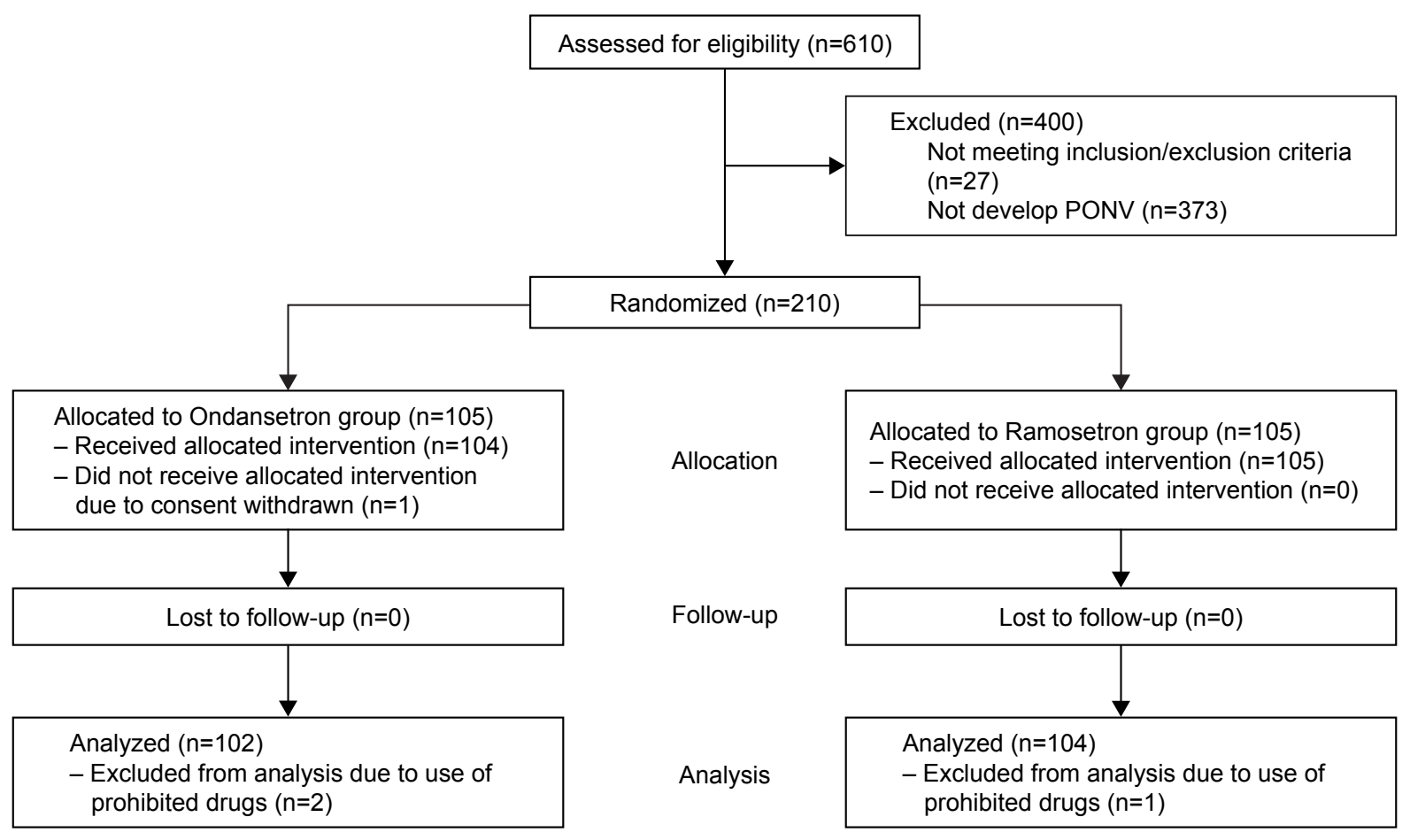

Figure I Flow diagram of the study. 
Table I Patient's characteristics

\begin{tabular}{|c|c|c|c|}
\hline & $\begin{array}{l}\text { Ondansetron } \\
\text { group } \\
(n=\mid 02)\end{array}$ & $\begin{array}{l}\text { Ramosetron } \\
\text { group } \\
(n=104)\end{array}$ & $P$-value \\
\hline Age (years) & $42.6 \pm 10.9$ & $43.7 \pm 11.9$ & 0.50 \\
\hline Women & $97(95.1)$ & $96(92.3)$ & 0.41 \\
\hline Body mass index $\left(\mathrm{kg} / \mathrm{m}^{2}\right)$ & $23.4 \pm 4.0$ & $23.2 \pm 3.1$ & 0.58 \\
\hline ASA physical status & & & 0.44 \\
\hline 1 & $83(81.4)$ & $79(76.0)$ & \\
\hline 2 & $20(19.6)$ & $25(24.0)$ & \\
\hline $\begin{array}{l}\text { History of PONV or motion } \\
\text { sickness }\end{array}$ & $38(37.3)$ & $42(40.4)$ & 0.65 \\
\hline Nonsmoking & $99(97.1)$ & $100(96.2)$ & 1.00 \\
\hline Simplified risk score & & & 0.78 \\
\hline 2 & $10(10.2)$ & II (I0.6) & \\
\hline 3 & 57 (55.9) & $59(56.7)$ & \\
\hline 4 & $35(34.3)$ & $34(32.7)$ & \\
\hline Duration of anesthesia (min) & $123.9 \pm 47.5$ & $121.4 \pm 66.2$ & 0.75 \\
\hline Duration of surgery (min) & $94.1 \pm 45.2$ & $92.2 \pm 64.6$ & 0.81 \\
\hline Duration of PACU stay (min) & $67.2 \pm 24.4$ & $70.6 \pm 25.6$ & 0.32 \\
\hline Use of fentanyl-based IV PCA & $70(68.6)$ & $59(56.7)$ & 0.08 \\
\hline Type of surgical procedure & & & 0.35 \\
\hline Cholecystectomy & $34(33.3)$ & $43(4 I .3)$ & \\
\hline Hysterectomy & $2 \mathrm{I}(20.6)$ & $18(17.3)$ & \\
\hline Ovarian cystectomy & $19(18.6)$ & $20(19.2)$ & \\
\hline Myomectomy & $19(18.6)$ & $13(12.5)$ & \\
\hline Salpingo-oophorectomy & $6(5.9)$ & $8(7.7)$ & \\
\hline Other gynecologic surgery & $3(2.9)$ & $2(1.9)$ & \\
\hline
\end{tabular}

Note: Values are presented as mean \pm standard deviation or number (\%) of patients. Abbreviations: ASA, American Society of Anesthesiologists; PONV, postoperative nausea and vomiting; PACU, postanesthesia care unit; IV PCA, intravenous patientcontrolled analgesia.

with $\geq 3$ risk factors for PONV was 92 (90.2\%) patients in the ondansetron group and $93(89.4 \%)$ patients in the ramosetron group.

Our primary outcome was ramosetron noninferiority in comparison with ondansetron based on the complete response rate for $24 \mathrm{~h}$ after administration of the study drug. The complete response rate was $44.1 \%$ (45 of 102 patients) and $52.9 \%$ (55 of 104 patients) in the ondansetron and ramosetron group, respectively, for $24 \mathrm{~h}$ after administration of the study drug (absolute difference 8.8\%, 95\% CI -4.8 to -22.4 ) (Figure 2). The incidence and severity of nausea
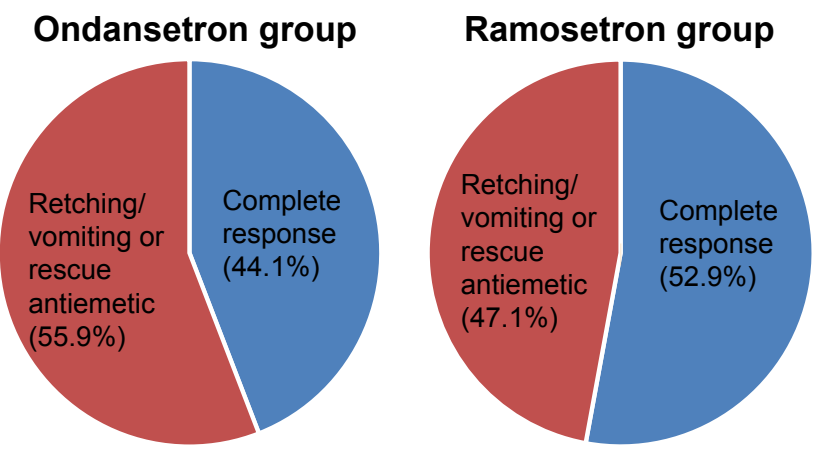

Figure 2 Complete response rate for $24 \mathrm{~h}$ after administration of the study drug.
Table 2 Incidence of nausea, retching/vomiting, and requirement for rescue antiemetic treatment

\begin{tabular}{|c|c|c|c|}
\hline & $\begin{array}{l}\text { Ondansetron } \\
\text { group } \\
(n=102)\end{array}$ & $\begin{array}{l}\text { Ramosetron } \\
\text { group } \\
(n=104)\end{array}$ & $P$-value \\
\hline \multicolumn{4}{|c|}{ Patients with nausea } \\
\hline $0-2 \mathrm{~h}$ & $70(68.6)$ & $64(61.5)$ & 0.29 \\
\hline $2-24 \mathrm{~h}$ & $59(57.8)$ & $57(54.8)$ & 0.66 \\
\hline $0-24 \mathrm{~h}$ & $83(81.4)$ & $77(74.0)$ & 0.21 \\
\hline \multicolumn{4}{|l|}{ Nausea severity } \\
\hline $\begin{array}{l}0-2 \mathrm{~h}(\mathrm{mild} / \\
\text { moderate/sev }\end{array}$ & $28 / 27 / 15$ & $27 / 27 / 10$ & 0.53 \\
\hline $\begin{array}{l}\text { 2-24 h (mild/ } \\
\text { moderate/sev }\end{array}$ & $21 / 31 / 7$ & $24 / 24 / 9$ & 0.84 \\
\hline \multicolumn{4}{|c|}{ Patients with retching/vomiting } \\
\hline $0-2 \mathrm{~h}$ & $10(9.8)$ & $15(14.4)$ & 0.31 \\
\hline $2-24 \mathrm{~h}$ & $14(13.7)$ & $16(15.4)$ & 0.74 \\
\hline $0-24 \mathrm{~h}$ & $22(21.6)$ & $27(26.0)$ & 0.46 \\
\hline \multicolumn{4}{|c|}{ Patients requiring rescue antiemetic } \\
\hline $0-2 \mathrm{~h}$ & $27(26.5)$ & $20(19.2)$ & 0.22 \\
\hline $2-24 \mathrm{~h}$ & $27(26.5)$ & $23(22.1)$ & 0.47 \\
\hline $0-24 \mathrm{~h}$ & $46(45.1)$ & $39(37.5)$ & 0.27 \\
\hline
\end{tabular}

Note: Values are presented as number (\%) of patients.

were similar between the two groups during the study period (Table 2). No differences were observed between the groups with respect to the incidence of retching and/or vomiting during the study period. The overall incidence of PONV during $24 \mathrm{~h}$ after administration of the study drug was $83(81.4 \%)$ in the ondansetron group and $78(75.0 \%)$ in the ramosetron group.

No patient withdrew from the study due to adverse events. There were no differences in the incidences of headache, dizziness, or drowsiness between the groups (Table 3). There were no significant differences with regard to the postoperative pain intensity and the rescue analgesic requirement during the study period (Table 4).

\section{Discussion}

In this prospective, randomized, double-blinded multicenter trial, we compared the therapeutic efficacy of a single dose of ramosetron $(0.3 \mathrm{mg})$ with that of a single dose of ondansetron (4 mg) in the treatment of established PONV in a moderate to high-risk population undergoing laparoscopic surgery

Table 3 Side effects of antiemetic drugs

\begin{tabular}{llll}
\hline & $\begin{array}{l}\text { Ondansetron } \\
\text { group } \\
(\mathbf{n}=1 \mathbf{1 0 2})\end{array}$ & $\begin{array}{l}\text { Ramosetron } \\
\text { group } \\
(\mathbf{n}=\mathbf{1 0 4})\end{array}$ & P-value \\
\hline Headache & $7(6.9)$ & $2(1.9)$ & 0.10 \\
Dizziness & II (10.8) & $14(13.5)$ & 0.56 \\
Drowsiness & I5 (14.7) & $17(16.3)$ & 0.75 \\
\hline
\end{tabular}

Note: Values are presented as number (\%) of patients. 
Table 4 Pain intensity scores and requirement of rescue analgesic

\begin{tabular}{clll}
\hline & $\begin{array}{l}\text { Ondansetron } \\
\text { group } \\
(\mathbf{n}=102)\end{array}$ & $\begin{array}{l}\text { Ramosetron } \\
\text { group } \\
\mathbf{( n = 1 0 4 )}\end{array}$ & P-value \\
\hline Pain scores & & & \\
0-2 h & $54.3 \pm 19.7$ & $51.5 \pm 20.5$ & 0.32 \\
2-24 h & $32.5 \pm 15.9$ & $34.9 \pm 16.8$ & 0.30 \\
Patients requiring rescue analgesic & & \\
0-2 h & $72(70.6)$ & $74(71.2)$ & 0.93 \\
2-24 h & 49 (48.0) & $54(51.9)$ & 0.58 \\
\hline
\end{tabular}

Note: Values are presented as mean \pm standard deviation or number (\%) of patients.

under general anesthesia. Noninferiority analysis revealed that ramosetron appears to be noninferior to ondansetron for the treatment of established PONV in this subset of patients for $24 \mathrm{~h}$ after administration of the study drug.

The etiology of PONV is multifactorial, with risk factors that include age, sex, obesity, a history of motion sickness or previous PONV, smoking habits, anesthetic technique, and postoperative use of opioids. ${ }^{11}$ Type of surgery as a risk factor is still debated; laparoscopic surgery is associated with a higher incidence of PONV when compared with open surgery due to $\mathrm{CO}_{2}$ insufflation, residual pneumoperitoneum, peritoneal distension, and diaphragm and visceral organ irritation. ${ }^{12}$ Several meta-analyses report that ondansetron is one of the most effective antiemetic agents available for prevention and treatment of PONV, suggesting that intravenous ondansetron $4 \mathrm{mg}$ was the optimal dose for treating established PONV..$^{9,13}$ However, little information exits on the therapeutic efficacy of a newly developed 5- $\mathrm{HT}_{3}$ receptor antagonist in patients with established PONV after laparoscopic surgery. In this study, we compared the clinical evidence for therapeutic response to ramosetron with that of ondansetron for established PONV treatment. There was no statistically significant difference between ramosetron and ondansetron as a treatment for established PONV after laparoscopic surgery in moderate to high-risk patients for $24 \mathrm{~h}$ after administration of the study drug.

In a recent meta-analysis comparing ramosetron to ondansetron for preventing PONV during various types of surgery, there was no difference in incidence of nausea, need for rescue antiemetics, and incidence of side effects, but there was significantly less vomiting in patients receiving ramosetron during early $(0-6 \mathrm{~h})$ and late $(6-24 \mathrm{~h})$ time periods. ${ }^{14-16}$ In this study, we had expected that ramosetron would have an advantage over ondansetron in treating vomiting or preventing further retching or vomiting in the late period because differences exist in receptor affinity, pharmacokinetics, and the half-life between ramosetron and ondansetron ( 9 vs $3.5 \mathrm{~h}$, respectively). ${ }^{17}$ Although differences did not reach statistical significance, $53 \%$ of patients receiving ramosetron treatment were prevented from further retching or vomiting without secondary rescue antiemetic administration compared to $44 \%$ of patients receiving ondansetron treatment. The current findings with ondansetron $(4 \mathrm{mg})$ are consistent with previous results evaluating ondansetron use for treating established PONV; the complete response rate at $24 \mathrm{~h}$ after ondansetron administration was $45 \%-47 \% .{ }^{9}, 18$

The incidence of PONV increases exponentially from $10 \%$ when no risk factors are present to $78 \%$ when all four risk factors are present, ${ }^{3}$ and identified risk factors include female gender, nonsmoking, the use of postoperative opioids, and prior history of motion sickness or PONV. The present study was designed to evaluate the therapeutic efficacy of ramosetron and ondansetron in patients at moderate to high risk of PONV, and thus we planned to include patients with two or more risk factors. However, after randomization and treatment allocation, we found that $90 \%$ of the enrolled patients had at least three risk factors, making our study unintentionally focused on high-risk patients. This may be due to the fact that the present study was done on the "treatment" of established PONV rather than its prevention, and theoretically, treatment studies are usually more difficult to perform. For instance, if a baseline risk of $40 \%$ PONV is expected, then of 100 patients who have given their informed consent to take part in a treatment trial, roughly 40 will eventually suffer from PONV symptoms and then be randomized and treated. The baseline risk for PONV after randomization could be increased compared to the general population, as patients with higher baseline risk of PONV would be more likely to develop PONV during the observation period for treatment decision. Although the $36 \%$ incidence of PONV during the first $2 \mathrm{~h}$ postrecovery of our study was found to rather accurately reflect common clinical practice, ${ }^{19}$ the observed complete response rates after treatment for established PONV may have led to different results if the enrolled patients had been more evenly distributed in terms of risks for PONV. Future studies are needed to validate the therapeutic efficacy of ramosetron in patients at relatively low risk of PONV.

In this study, there were no differences in the incidence of adverse events such as headache, dizziness, and drowsiness between the groups. Excessive sedation and extrapyramidal symptoms also were not observed in any patients. VAS scores of postoperative pain and requirement of rescue analgesics were similar in both groups.

Our study had limitations. First, we compared two 5- $\mathrm{HT}_{3}$ antagonists and did not use a placebo control group. However, given the high risk of PONV associated with 
patient-related factors and surgery type, having a placebo arm was considered unethical. Valid data on the therapeutic efficacy and dose-response of other classic antiemetics are needed. Second, we observed therapeutic responses during $24 \mathrm{~h}$ after administration of the study drug. Since the longer efficacy of ramosetron compared with ondansetron has been demonstrated, ramosetron could prevent further PONV development longer than $24 \mathrm{~h}$ after administration of the study drug.

\section{Conclusion}

We observed evidence to support the noninferiority of ramosetron $(0.3 \mathrm{mg})$ compared to ondansetron $(4 \mathrm{mg})$ for the treatment of established PONV in moderate to high-risk patients undergoing laparoscopic surgery.

\section{Acknowledgment}

The trial is supported by a research grant (AKR-NA-2015-01) from Astellas Pharma Korea, Inc.

\section{Disclosure}

Sang-Hwan Do and Hee Jung Baik report consultancy payment from Astellas Pharma Korea, Inc. Yong Seon Choi, Sang-Hwan Do, Kyeong Tae Min, and Hee Jung Baik report payment for lectures from Astellas Pharma Korea, Inc. All authors report no other conflicts of interest in this work.

\section{References}

1. Cohen MM, Duncan PG, DeBoer DP, Tweed WA. The postoperative interview: assessing risk factors for nausea and vomiting. Anesth Analg. 1994;78(1):7-16.

2. Stadler M, Bardiau F, Seidel L, Albert A, Boogaerts JG. Difference in risk factors for postoperative nausea and vomiting. Anesthesiology. 2003;98(1):46-52.

3. Apfel CC, Läärä E, Koivuranta M, Greim CA, Roewer N. A simplified risk score for predicting postoperative nausea and vomiting: conclusions from cross-validations between two centers. Anesthesiology. 1999;91(3): 693-700.

4. Gan TJ, Meyer T, Apfel CC, et al; Department of Anesthesiology, Duke University Medical Center. Consensus guidelines for managing postoperative nausea and vomiting. Anesth Analg. 2003;97(1):62-71.
5. Choi YS, Shim JK, Yoon DH, Jeon DH, Lee JY, Kwak YL. Effect of ramosetron on patient-controlled analgesia related nausea and vomiting after spine surgery in highly susceptible patients: comparison with ondansetron. Spine (Phila Pa 1976). 2008;33(17):E602-E606.

6. Roh GU, Yang SY, Shim JK, Kwak YL. Efficacy of palonosetron versus ramosetron on preventing opioid-based analgesia-related nausea and vomiting after lumbar spinal surgery: a prospective, randomized, and double-blind trial. Spine (Phila Pa 1976). 2014;39(9):E543-E549.

7. Swaika S, Pal A, Chatterjee S, Saha D, Dawar N. Ondansetron, ramosetron, or palonosetron: which is a better choice of antiemetic to prevent postoperative nausea and vomiting in patients undergoing laparoscopic cholecystectomy? Anesth Essays Res. 2011;5(2):182-186.

8. Bodner M, White PF. Antiemetic efficacy of ondansetron after outpatient laparoscopy. Anesth Analg. 1991;73(3):250-254.

9. Claybon L. Single dose intravenous ondansetron for the 24-hour treatment of postoperative nausea and vomiting. Anaesthesia. 1994;49 (Suppl): 24-29.

10. Pearman MH. Single dose intravenous ondansetron in the prevention of postoperative nausea and vomiting. Anaesthesia. 1994;49 (Suppl): $11-15$.

11. Watcha MF, White PF. Postoperative nausea and vomiting. Its etiology, treatment, and prevention. Anesthesiology. 1992;77(1):162-184.

12. Apfel CC, Heidrich FM, Jukar-Rao S, et al. Evidence-based analysis of risk factors for postoperative nausea and vomiting. Br J Anaesth. 2012; 109(5):742-753.

13. Tramèr MR, Reynolds DJ, Moore RA, McQuay HJ. Efficacy, doseresponse, and safety of ondansetron in prevention of postoperative nausea and vomiting: a quantitative systematic review of randomized placebo-controlled trials. Anesthesiology. 1997;87(6):1277-1289.

14. Pinsornsak P, Teeyaphudit M, Ruetiwarangkoon C, Chaiwuttisak A. Comparison of ramosetron with ondansetron for prevention of intrathecal morphine-induced nausea and vomiting after primary total knee arthroplasty: a randomized control trial. J Arthroplasty. 2017;32(3): 1040-1043.

15. Mihara T, Tojo K, Uchimoto K, Morita S, Goto T. Reevaluation of the effectiveness of ramosetron for preventing postoperative nausea and vomiting: a systematic review and meta-analysis. Anesth Analg. 2013; 117(2):329-339.

16. Gao C, Li B, Xu L, et al. Efficacy and safety of ramosetron versus ondansetron for postoperative nausea and vomiting after general anesthesia: a meta-analysis of randomized clinical trials. Drug Des Devel Ther. 2015;9:2343-2350.

17. Gan TJ. Selective serotonin 5-HT3 receptor antagonists for postoperative nausea and vomiting: are they all the same? CNS Drugs. 2005;19(3):225-238.

18. Scuderi P, Wetchler B, Sung YF, et al. Treatment of postoperative nausea and vomiting after outpatient surgery with the 5-HT3 antagonist ondansetron. Anesthesiology. 1993;78(1):15-20.

19. Tramèr MR, Moore RA, Reynolds DJ, McQuay HJ. A quantitative systematic review of ondansetron in treatment of established postoperative nausea and vomiting. BMJ. 1997;314(7087):1088-1092.
Therapeutics and Clinical Risk Management

\section{Publish your work in this journal}

Therapeutics and Clinical Risk Management is an international, peerreviewed journal of clinical therapeutics and risk management, focusing on concise rapid reporting of clinical studies in all therapeutic areas, outcomes, safety, and programs for the effective, safe, and sustained use of medicines. This journal is indexed on PubMed Central, CAS,

\section{Dovepress}

EMBase, Scopus and the Elsevier Bibliographic databases. The manuscript management system is completely online and includes a very quick and fair peer-review system, which is all easy to use. Visit http://www.dovepress.com/testimonials.php to read real quotes from published authors. 